\title{
Retraction Note to: Radiographic characteristics that delineate abusive from accidental skull fractures, including the significance of fracture extension to sutures
}

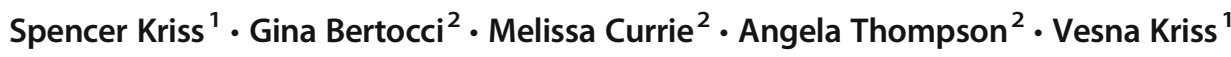 \\ Published online: 6 December 2019 \\ (C) Springer-Verlag GmbH Germany, part of Springer Nature 2019
}

Retraction note to: Pediatr Radiol (2018) 48 (Suppl 1):S1-S298

https://doi.org/10.1007/s00247-018-4130-z

The authors have retracted abstract \#029 "Radiographic characteristics that delineate abusive from accidental skull fractures, including the significance of fracture extension to sutures," page S95, because the study lacked appropriate ethical oversight from a relevant ethics committee. All authors agree to this retraction.

The online version of the original article can be found at https://doi.org/ $10.1007 / \mathrm{s} 00247-018-4130-\mathrm{z}$

Spencer Kriss

skriss2018@gmail.com

1 Norton Children's Hospital, Louisville, KY 40018, USA

2 University of Louisville, Louisville, KY, USA 